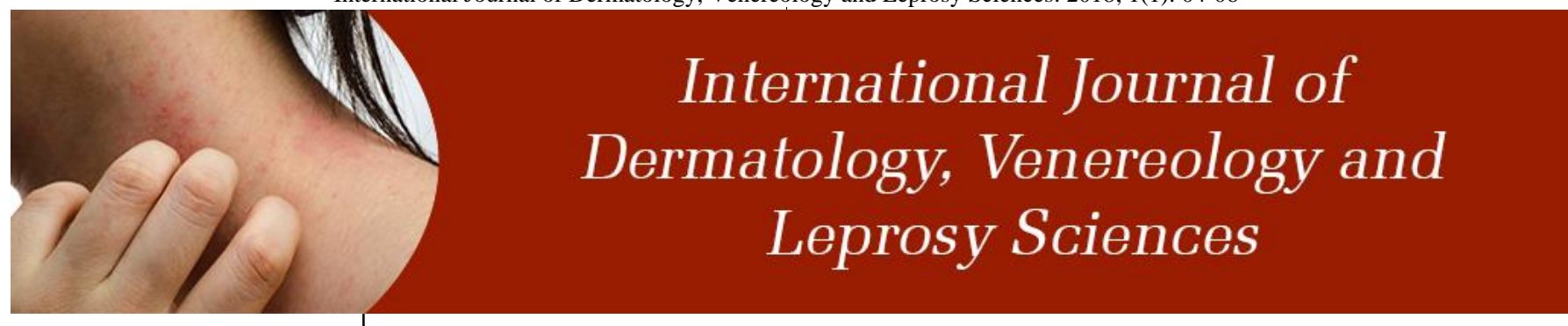

E-ISSN: 2664-942X

P-ISSN: 2664-9411

www.dermatologypaper.com/

Derma 2018; 1(1): 04-06

Received: 04-11-2017

Accepted: 06-12-2017

Dr. Sohel Khan

Department of Dermatology,

Anwer Khan Modern Medical

College Hospital, Dhaka,

Bangladesh
Corresponding Author:

Dr. Sohel Khan

Department of Dermatology,

Anwer Khan Modern Medical

College Hospital, Dhaka,

Bangladesh

\section{Occurrence of acne vulgaris in adult population: A clinical study}

\section{Dr. Sohel Khan}

DOI: $\underline{\text { https://doi.org/10.33545/26649411.2018.v1.i1a.2 }}$

\begin{abstract}
Background: Acne vulgaris is a common skin disease affecting approximately $9.4 \%$ of the world's population. The present study was conducted to evaluate the cases of Acne vulgaris in patients.

Materials \& Methods: The present study was conducted on 125 patients of both genders. In all patients, duration of acne, type of skin (dry/normal/oily), site of lesion (face, chest, or back), grade of acne, postacne hyperpigmentation (present/absent) and acne scars were recorded.

Results: Out of 125 participants, males were 55 and females were 70 . Common site was face \& chest in 50, back in 35, face in 20 and chest $\&$ back in 20 cases. The difference was significant $(P<0.05)$. Grade I was seen in 15, grade II in 50, grade III in 40 and grade IV in 20 patients. The difference was significant $(P<0.05)$. Acne grading was mild in 60 , moderate in 45 and severe in 20 . The difference was significant $(P<0.05)$.

Conclusion: Acne vulgaris is quite common in females as compared to males. Common site was face $\&$ chest.
\end{abstract}

Keywords: Acne vulgaris, Females, Face

\section{Introduction}

Acne vulgaris is a common skin disease affecting approximately $9.4 \%$ of the world's population with the highest prevalence in adolescents [1]]. It affects over $90 \%$ of males and $80 \%$ of females in all ethnic groups. The prevalence of acne in adolescents and adults varies among countries and ethnic groups ${ }^{[2]}$. The clinical and histological features of acne, a chronic inflammatory disease of the pilosebaceous unit, are well described. Acne lesions are typically classified as non-inflammatory (open and closed comedones) or inflammatory (papules and pustules). Seborrhoea, or grease production, is also a feature. Scarring is often present following inflammation. The pathophysiological events occurring in acne are also relatively well studied [3]. Lesions start when keratinocytes lining the hair follicle desquamate creating a microcomedone. At puberty increased sebum production creates an environment that can sustain the colonization of Propionibacterium acnes. As P. acnes proliferates, inflammatory and chemotactic mediators are produced, which in turn drive inflammatory processes ${ }^{[4]}$.

The major complications of acne are scarring and psychosocial distress which persists long after active lesions have disappeared. Psychosocial effects of acne vulgaris have been long identified, but this sequelae of acne remain under evaluated ${ }^{[5]}$. Patients with acne have been shown to have levels of social, psychological, and emotional impairments similar to serious diseases such as asthma, epilepsy, diabetes, or arthritis. These patients are more prone to embarrassment, social withdrawal, depression, anxiety, and anger ${ }^{[6]}$. The present study was conducted to evaluate the cases of Acne vulgaris in patients.

\section{Materials \& Methods}

The present study was conducted in the department of Dermatology. It comprised of 125 patients of both genders. The study was approved from institutional ethical committee. All participants were informed regarding the study and written consent was obtained.

Information such as name, age, gender etc. was recorded. In all patients, duration of acne, type of skin (dry/normal/oily), site of lesion (face, chest, or back), grade of acne, postacne hyperpigmentation (present/absent) and acne scars were recorded. Results thus obtained were subjected to statistical analysis. $\mathrm{P}$ value less than 0.05 was considered significant. $\mathrm{P}$ value less than 0.05 was considered significant. 


\section{Results}

Table I: Distribution of patients

\begin{tabular}{|c|c|c|}
\hline & Total- 125 & \\
\hline Gender & Males & Females \\
\hline Number & 55 & 70 \\
\hline
\end{tabular}

Table I shows that out of 125 participants, males were 55 and females were 70 .

Table II: Site of Acne

\begin{tabular}{|c|c|c|}
\hline Site & Number & \multirow{2}{*}{ P value } \\
\hline Face & 20 & \multirow{2}{*}{0.01} \\
\hline Back & 35 & \\
\hline Face \& Chest & 50 & \\
\hline Chest \& Back & 20 & \\
\hline
\end{tabular}

Table II shows that common site was face \& chest in 50, back in 35 , face in 20 and chest $\&$ back in 20 cases. The difference was significant $(P<0.05)$.

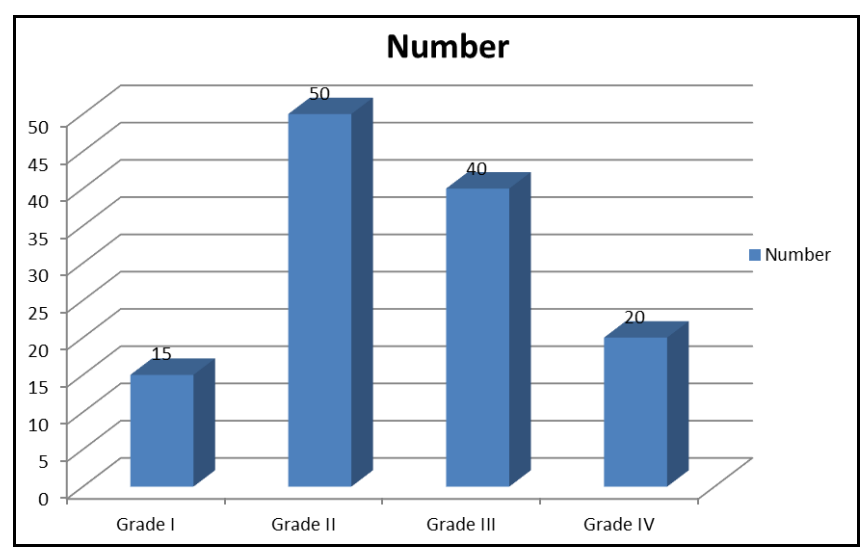

Graph I: Grading of Acne vulgaris

Graph I shows that grade I was seen in 15 , grade II in 50 , grade III in 40 and grade IV in 20 patients. The difference was significant $(P<0.05)$.

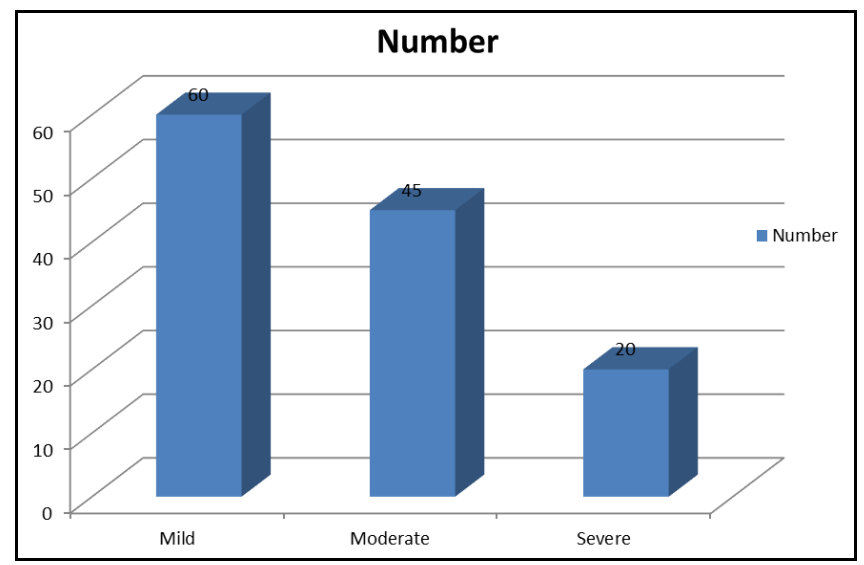

Graph II: Severity of Acne scars

Graph II shows that acne grading was mild in 60 , moderate in 45 and severe in 20 . The difference was significant $(P<$ $0.05)$.

\section{Discussion}

A degree of acne affects nearly all people between the ages of 15 and 17 years and in 15-20\% of young people, acne is moderate to severe. Prevalence rates of acne by age and 1996 census data estimated that 40-50million U.S. individuals have acne, with an $85 \%$ prevalence rate in those aged 12-24 years. The present study was conducted to evaluate the cases of Acne vulgaris in patients.

We found out of 125 participants, males were 55 and females were 70. A study by Lucky et al. ${ }^{[6]}$ found that the severity of acne in boys correlated with pubertal maturation and that $50 \%$ of 10- and 11- year- old boys had more than 10 comedones.

In present study, common site was face \& chest in 50, back in 35 , face in 20 and chest $\&$ back in 20 cases. Grade I was seen in 15 , grade II in 50, grade III in 40 and grade IV in 20 patients. Saitta et al. ${ }^{[7]}$ found that most cases $(64 \%)$ were between 15 and 20 years. Females (57\%) outnumbered males. Facial lesions $(61.4 \%)$ and grade II acne were most common. Mean DLQI score was 7.22. DLQI scores were statistically influenced by the age of the patient, duration and grade of acne, acne scar, and postacne hyperpigmentation. This study showed significant impairment of QoL in acne patients. Assurance and counseling along with early treatment of acne vulgaris are important to reduce disease related psychosocial sequelae and increase the efficacy of treatment.

We found that acne grading was mild in 60 , moderate in 45 and severe in 20. The degree of impairment in QOL significantly increased with increase of clinical severity of acne, with presence of post acne hyper pigmentation and scarring. The same has been reported by Tasoula et al. ${ }^{[8]}$ who reported a negative correlation between acne severity and better quality of life. However, other studies reported no significant association between severity of acne and QOL.

Acne begins in the early teens with the onset of facial sebum production and facial comedones followed by inflammatory lesions. Acne can occur in prepubertal children but this is usually noninflammatory in nature as children have not yet begun production of sebum, which provides the correct environment to host P. acnes. Around 20\% of neonates have an acneiform eruption but this usually resolves by 3 months. One study has shown that the average age at onset of puberty in boys has dropped from 11.92 to 11.66 years over a 15- year period ${ }^{[9]}$.

Hazarika et al. ${ }^{[10]}$ postulated that this younger age of puberty was the reason for the observation that younger patients between the ages of 8 and 11 were presenting with acne in their clinics. Acne is a chronic disease and can persist, in some cases, into adulthood. Hayashi et al ${ }^{11}$ observed acne scars in $90.8 \%$ and opined that acne scars had a negative impact on patient's QoL. Seventy- three percentage of subjects in this study had acne scars. There was a statistically significant association between acne scars and DLQI scores in this study $(P<0.05)$. Furthermore, gender difference in acne scars in this study was statistically significant $(P<0.05)$. Kulanthan et al. ${ }^{[12]}$ found two thirds of acne patients to have oily skin. In this study, $61.4 \%$ had oily skin, and the relation between severity of acne and oiliness was statistically significant. The limitation of the study was the sample size was small. A thorough cases analysis was not done.

\section{Conclusion}

Acne vulgaris is quite common in females as compared to males. Common site was face $\&$ chest.

\section{References}

1. Lello J, Pearl A, Arroll B, Yallop J, Birchall NM. 
Prevalence of acne vulgaris in Auckland senior high school students. N Z Med J. 1995; 108:287-9.

2. Barnes LE, Levender MM, Fleischer AB Jr, Feldman SR. Quality of life measures for acne patients. Dermatol Clin. 2012; 30:293-300

3. Ismail KH, Mohammed-Ali KB. Quality of life in patients with acne in Erbil city. Health Qual Life Outcomes. 2012; 10:60.

4. Shuster S, Fisher GH, Harris E, Binnell D. The effect of skin disease on self image [proceedings]. $\mathrm{Br} \mathrm{J}$ Dermatol. 1978; 99:18-9.

5. Aktan S, Ozmen E, Sanli B. Anxiety, depression, and nature of acne vulgaris in adolescents. Int J Dermatol. 2000; 39:354-7.

6. Lucky AY, Khan GK. Dermatology Life Quality Index (DLQI) - A simple practical measure for routine clinical use. Clin Exp Dermatol. 1994; 19:210-6.

7. Saitta P, Grekin SK. A Four question Approach to Determining the Impact of Acne Treatment on Quality of Life. J Clin Aesthet Dermatol. 2012; 5:51-7.

8. Tasoula E, Gregoriou S, Chalikias J, Lazarou D, Danopoulou I, Katsambas A et al. The impact of acne vulgaris on quality of life and psychic health in young adolescents in Greece. Results of a population survey. An Bras Dermatol. 2012; 87:862-9.

9. Shah J, Parmar D. A Complete Review on Acne Vulgaris. J Adv Med Dent Scie Res. 2015; 3(4):20-24.

10. Hazarika N, Rajaprabha RK. Assessment of life quality index among patients with acne vulgaris in a suburban population. Indian J Dermatol. 2016; 61:163-8.

11. Hayashi N, Miyachi Y, Kawashima M. Prevalence of scars and "mini scars", and their impact on quality of life in Japanese patients with acne. J Dermatol. 2015; 42:690-6.

12. Kulthanan K, Jiamton S, Kittisarapong R. Dermatology Life Quality Index in Thai patients with acne. Siriraj Med J. 2007; 59:3-7. 